\title{
Dos bens imóveis rurais aos bens imóveis urbanos: melhoramentos no espaço urbano de um município nascente, Varginha na passagem para o século XX
}

From rural properties to urban properties: improvements in the urban space of a newbor munipality, Varginha on the passage to the 20th century

De los bienes inmuebles rurales a los bienes inmuebles urbanos: mejoras en el espacio urbano de un municipio nascente, Varginha en el pasaje para el siglo XX De l'immobilier rural à l'immobilier urbain: amélioration de l'espace urbain d'une municipalité naissante, Varginha dans la transition vers le XXe siècle

\section{Natânia Silva Ferreira}

\section{(2) OpenEdition}

\section{Journals}

\section{Edição electrónica}

URL: http://journals.openedition.org/espacoeconomia/10004

DOI: 10.4000/espacoeconomia.10004

ISSN: 2317-7837

\section{Editora}

Núcleo de Pesquisa Espaço \& Economia

Refêrencia eletrónica

Natânia Silva Ferreira, « Dos bens imóveis rurais aos bens imóveis urbanos: melhoramentos no espaço urbano de um município nascente, Varginha na passagem para o século XX », Espaço e Economia [Online], 16 | 2019, posto online no dia 04 janeiro 2020, consultado o 10 janeiro 2020. URL : http://journals.openedition.org/espacoeconomia/10004; DOI : 10.4000/espacoeconomia.10004

Este documento foi criado de forma automática no dia 10 janeiro 2020.

(c) NUPEE 


\section{Dos bens imóveis rurais aos bens imóveis urbanos: melhoramentos no espaço urbano de um município nascente, Varginha na passagem para o século XX}

From rural properties to urban properties: improvements in the urban space of a newbor munipality, Varginha on the passage to the 20th century

De los bienes inmuebles rurales a los bienes inmuebles urbanos: mejoras en el espacio urbano de un municipio nascente, Varginha en el pasaje para el siglo XX De l'immobilier rural à l'immobilier urbain: amélioration de l'espace urbain d'une municipalité naissante, Varginha dans la transition vers le XXe siècle Natânia Silva Ferreira

\section{Introdução: a passagem para o século XX como uma época de mudanças no cotidiano}

1 A transição para o século XX foi um período de melhoramentos urbanos e crescimento para grande parte do Brasil, pois diferentes regiões se desenvolveram, com o aumento de cidades e a introdução de empresas de serviços urbanos - como as de portos, telefonia e energia elétrica -, a chegada das ferrovias e dos estabelecimentos comerciais, das indústrias e das instituições bancárias (SAES, 2008, cap. 5). Tais elementos davam nova forma ao Brasil, com auxílio de atividades agropecuárias que reforçavam as dinâmicas econômicas regionais.

Em Manaus, o ciclo da borracha se constituiu num exemplo de economia particular, porque possibilitou crescimento e industrialização da localidade (BUENO, 2012). Na Bahia, o cacau formou uma economia de exportação específica do estado (ALMEIDA, 
2009). No Rio Grande do Sul houve a formação de uma economia própria, baseada na pecuária (HERRLEIN JR., 2000). Em São Paulo, o café possibilitou fortalecimento da indústria regional e expansão das exportações nacionais (CANO, 1975). Na Zona da Mata e no Sul de Minas Gerais, a cafeicultura também promoveu dinamização econômica (WIRTH, 1982).

3 Naquele contexto, padrões de consumo diferenciados fizeram parte do cotidiano das elites locais, o que não era especificidade apenas do Brasil. A partir da década de 1880, “(...) o impacto da Revolução Científico-Tecnológica se faz sentir na sua plenitude, alterando tanto os hábitos e costumes cotidianos quanto o ritmo e intensidade dos transportes, comunicações e do trabalho (...)" (SEVCENKO, 1998, p. 11). Grosso modo, o mundo sentiu os efeitos da Segunda Revolução Industrial. "No curso de seus desdobramentos surgirão, apenas para se ter uma breve ideia, os veículos automotores, os transatlânticos, os aviões, o telégrafo, o telefone, a iluminação elétrica e a ampla gama de utensílios eletrodomésticos (...)" (SEVCENKO, 1998, p. 09).

4 No Brasil, tais transformações (modernização e urbanização do país, alterações de padrões de consumo e hábitos de vida cotidianos) marcavam o período da Primeira República. Época aquela que, em diferentes regiões, municípios se emancipavam e passavam por evolução em seus espaços urbanos.

A aurora do regime republicano dava-se em meio a transformações demográficas e sociais, que liberavam populações, e franqueava novos destinos geográficos às esperanças de sobrevivência de muitos dos velhos e novos brasileiros (...) As grandes cidades surgiam no horizonte como o espaço das novas possibilidades de vida, do esquecimento das mazelas do campo, da memória do cativeiro (MARINS, 1988, p. 132).

5 Transformações sociais, políticas, culturais, econômicas e urbanas marcaram o cotidiano da passagem para o século XX. E foi em meio àquelas transformações que, em 1882, nasceu o município de Varginha, situado ao Sul de Minas Gerais. Fizeram parte da formação inicial do município os distritos de Pontal (emancipado em 1911) e Carmo da Cachoeira (emancipado em 1938).

Dessa forma, o objetivo deste artigo é o de compreender os melhoramentos no espaço urbano da cidade de Varginha e de seus dois distritos, com destaque para os projetos e leis dos vereadores da Câmara Municipal e para as transações de registros de imóveis do município, entre os anos de 1882 até 1920.

7 As análises se iniciam em 1882 porque foi "aos dezecete dias do mez de dezembro de mil oitocentos e oitenta e dois (...) a hora que pelo Senhor Presidente da municipallidade da cidade de Três Pontas (...) foi marcada para a installação e posse desta Villa" i que ocorreu a primeira reunião da Câmara Municipal de Varginha. As discussões terminam no ano de 1920 porque esta década constitui um período de transformações para a economia brasileira que, de certa forma, podem ter refletido na sociedade varginhense. Segundo Wilson Cano, "a década de 1920, para o Brasil, representa um processo de transição econômica e social, a partir do chamado modelo primário exportador, rumo a um novo padrão de acumulação - o do crescimento para dentro (...)" (CANO, 2012, p. 898).

80 conjunto de fontes históricas principais utilizado corresponde a cerca de 500 atas da Câmara Municipal de Varginha (ACMV) localizadas no Museu Municipal da cidade (MMV) e 2.085 registros de imóveis do município, localizados no Cartório de Registros de Imóveis de Varginha (CRIV). Como fontes complementares, serão utilizados o Código 
de Posturas de Varginha (CPV), do ano de 1888, o Almanach Sul-Mineiro para o ano de 1884 e inventário post-mortem de personagem do município, localizado atualmente no Arquivo Permanente do Tribunal de Justiça de Minas Gerais, na cidade de Contagem.

Para o cumprimento do objetivo, este texto conta com 3 seções, além desta Introdução. Na seção dois, as principais fontes utilizadas serão as atas da Câmara, e será abordado a respeito da emancipação do município de Varginha e os melhoramentos do espaço urbano considerando os projetos e leis aprovados na Câmara Municipal. Na seção três, o destaque vai para os registros de imóveis, sendo está seção dividida em dois tópicos: o primeiro ressaltará as transações de imóveis rurais e urbanos do município (Varginha e seus dois distritos); o segundo tratará da valorização do espaço urbano da cidade de Varginh ${ }^{\text {ii }}$. A seção quatro trás as considerações finais.

\section{As atas da Câmara Municipal e os projetos e leis dos vereadores: transformações no espaço urbano varginhense}

A região do Sul de Minas Gerais, onde se situa Varginha, foi emancipada em 1789, com a paróquia de Campanha da Princesa. Localizada a princípio na Comarca do Rio das Mortes, Campanha se tornou a sede da Comarca do Rio Sapucaí a partir do ano de 1833, tendo suas fronteiras delimitadas ao norte pelo Rio Grande e ao sul e sudeste pela serra da Mantiqueira.

11 O município de Campanha foi desmembrado na primeira metade do século XIX em seis outros municípios: Baependy (1814), Jacuhy (1814), Pouso Alegre (1831), Lavras (1831), Jaguary (1840) e Itajubá (1848). Varginha, porém, fez parte de um outro grupo de municípios do Sul de Minas, que se emancipou ao final do século XIX com a fortificação da economia cafeeira pelo sul mineiro (SAES; COSENTINO; GAMBI, 2012, p. 31).

Varginha foi emancipada do município de Três Pontas no ano de 1882, com a ocorrência da primeira reunião da Câmara Municipal varginhense naquele ano, onde foram escolhidos o primeiro presidente da Câmara Municipal, Matheus Tavares da Silva ${ }^{\text {iii, }}$ e o vice presidente, José Maximiano Baptista ${ }^{\text {iv }}$.

O município nascente teve como principal atividade econômica no início do século XX a cafeicultura, que contribuiu para a dinamização das exportações locais. Em 1918, por exemplo, a média de exportações de café que passava pela estação local da Estrada de Ferro Muzambinho chegou a atingir 200 mil sacas, sendo 125 mil dessas sacas produzidas na cidade de Varginha, mas incluída a produção do distrito de Carmo da Cachoeira, que ainda não havia se emancipado. As 75 mil sacas restantes eram de municípios vizinhos (LEFORT, 1950 apud SALES, 2003, p. 285).

Além disso, o cotidiano varginhense do período de 1882 até 1920 contava com algumas casas comerciais e de serviços: farmácias, consultórios médicos, comércios de venda por atacado e varejo, salões de barbeiros e cabeleireiros, alfaiatarias, hotéis, pensões, oficinas de sapateiros, selarias, dentistas (SALES, 2003, p. 280-281). Algumas fábricas também formavam o município na época: uma fábrica de vinhos, uma de meias de lã, estabelecimentos de beneficiar café e os estabelecimentos de aguardente, rapadura, manteiga, e as oficinas mecânicas (FONSECA \& LIBERAL, 1920 apud SALES, 2003, p. 208-281). As instituições bancárias presentes eram uma agência do Banco do Brasil, instalada em 1912, e uma do Banco Hypotecário e Agrícola do Estado de Minas Geraes, instalada em 1915. 
O processo de urbanização pelo qual o Brasil passou na mudança do século XIX para o século XX também ocorreu em Varginha, embora de forma particular, e contou com o auxílio dos grupos de vereadores do município, que a cada formação da Câmara Municipal tentavam inserir o município de Varginha de forma ativa na economia e sociedade sul mineira, por meio dos projetos e leis voltados para a urbanização local.

Assunto recorrente nas atas da Câmara era a manutenção de estradas e pontes. No dia 20 de abril de 1886, por exemplo, foi criada uma comissão com "os Cidadãos José Pinto Ribeiro, e João da Silva Figueiredo Galvão, para hirem no dito lugar [estrada no lugar denominado Linha] e darem enformações a esta Camara, sobre a mesma estrada" (ACMV, 1886, fl. 51)v.

A atuação da Câmara Municipal, vale ressaltar, caminhava conjuntamente com as novas normas que iam surgindo do município, pois o espaço urbano deveria passar por cuidados que antes não eram relevantes. No capítulo III do primeiro Código de Posturas de Varginha, do ano de 1888, a seção "do aceio e embelezamento da cidade e povoações", estabelecia que era "prohibido manchar paredes, portas, janellas e muros com qualquer materia immunda, ou escrever letreiros, desenhos allusivos ou obscenos: multa de 30\$ e prisão por 5 dias" (CPV, 1888, p. 344). Na seção "da limpeza, salubridade da agua, ar e alimentos", o artigo 40 dizia, dentre outros, que era proibido "ter chiqueiros nos pateos, nos centros da povoação; sob pena de ser multado na quantia de $10 \$$ a $30 \$$ ” (CPV, 1888, p. 344).

18 Tanto as mudanças mais simples, como as assinaladas pelo Código de Posturas, até as de maior fôlego para a época, como a inauguração da ferrovia, a chegada da energia elétrica e das linhas telefônicas, que serão descritas neste texto, estavam inseridas num processo maior, de modernização de padrões de consumo e de hábitos de vida, em que os costumes do cotidiano iam se alterando nas mais diversas localidades, inclusive nos municípios em formação, como era o caso de Varginha e de outros municípios sul mineiros na passagem para o século $\mathrm{XX}^{\mathrm{vi}}$.

9 No final do século XIX, Varginha passou a contar com uma inovação para o município: no dia 28 de maio de 1892, uma estação da Estrada de Ferro Muzambinho, partindo do município vizinho de Três Corações, foi inaugurada.

O projeto original da Companhia Estrada de Ferro Muzambinho não contava com uma estação em Varginha, especialmente porque os terrenos no município eram mais elevados que o nível do rio. Para que a ferrovia passasse por Varginha, os custos aumentariam e, dessa forma, uma intervenção particular resolveu a questão. 0 auxílio financeiro partiu do major Matheus Tavares da Silva, primeiro presidente da Câmara Municipal varginhense, que se dispôs a pagar o necessário para a construção de uma estação na cidade (SALES, 2003). No inventário do major há uma passagem dizendo que "declarou mais o inventariante que o espólio possui uma cautela da Estrada Muzambinho". O valor da cautela era de 50 contos de réis (Inventário de Matheus Tavares da Silva, 1905, Arquivo Permanente do Tribunal de Justiça de Minas Gerais).

Matheus Tavares da Silva, além de ter sido o primeiro presidente da Câmara do município, tendo feito parte da elite política local, estava dentre os moradores mais ricos de Varginha (com um monte mor de cerca de 444 contos de réis ${ }^{\text {vii }}$, riqueza alta, considerando demais inventariados de Varginha do mesmo período do falecimento do major, o início do século XX viii). 0 major possuía distintos bens móveis e imóveis em seu processo de inventário, como diversas casas para empregados no espaço rural e casas de morada e estabelecimentos comerciais no espaço urbano. Mais que almejar o 
progresso da cidade, Matheus Tavares da Silva, como negociante, comerciante, fazendeiro e produtor de café, financiou parte da ferrovia porque o serviço seria necessário para a expansão de seus investimentos.

Os anos após 1910 foram importantes para a evolução do espaço urbano varginhense: os serviços de abastecimento de água potável passaram por melhorias, foi instalada a energia elétrica, linhas telefônicas entraram em funcionamento no município.

Na reunião de 09 de junho de 1910, sob presidência do coronel João Urbano de Figueiredo, "pelo vereador Antonio Rotundo foi apresentado um projecto de lei auctorizando ao Agente Executivo a chamar concorrencia publica para installação de luz elétrica, rede de esgotos e novo abastecimento d'agua (...)" (ACMV, 1910, fl. 04).

Ainda que as discussões a respeito da energia elétrica tenham começado no ano de 1910, foi em 1912 que, efetivamente, se iniciaram os projetos para a instalação. Na reunião extraordinária de 10 de fevereiro de 1912, sob presidência do major Silva Bittencourt, foram analisadas as propostas para a instalação da energia elétrica, tendo sido levadas oito propostas para avaliação dos vereadores. Foram elencados alguns requisitos por parte deles:

economico, conciliando o interesse público com o particular, energia eletrica sob o ponto de vista de sua importancia, encampação, condições de pagamento da Camara Municipal, favores extraordinarios pedidos pelos proponentes e vantagens extraordinarias pelos mesmos offerecidos (ACMV, 1912, fl. 30).

Depois das análises feitas, chegou-se à conclusão de que proposta vencedora foi a da Companhia Vivaldi, com sede no Rio de Janeiro.

Após dois anos daquela reunião de 1912, terminado o serviço pela Companhia, "aos doze dias do mez de Abril de mil novecentos e quatorze, as 18 horas (da tarde), no Theatro Municipal", deu-se início à sessão especial de instalação da luz elétrica (ACMV, 1914, fl. 73).

O novo serviço que chegava à Varginha não beneficiaria a população toda. Deve-se destacar que seriam iluminadas as áreas centrais da cidade, o espaço urbano. Os serviços de iluminação chegariam especialmente aos proprietários de comércios e fábricas, devido às suas atividades, e à minoria da população, como por exemplo, à família de Matheus Tavares da Silva, que detinha negócios e propriedades no espaço urbano.

Outra mudança da época foi a promovida pela introdução das linhas telefônicas. O assunto apareceu numa ata do ano de 1913, do dia 25 de junho, quando "foi apresentado pela comissão de obras públicas o parecer da mesma sobre uma petição do Senhor José Lisbôa de Paiva pedindo privilegio para estabelecer linhas telephonicas no município" (ACMV, 1913, fl. 56).

29 Nas atas da Câmara não houve descrição a respeito da instalação de linhas telefônicas, mas é verossímil afirmar que o projeto foi firmado. No açougue do senhor Manoel Caetano de Oliveira, que entrou em funcionamento no prédio do mercado em 1916, faria parte das instalações do cômodo "um telephone e uma lampada electrica" (ACMV, 1916, p. 39). Certamente, o novo serviço se restringiu à pequena parcela da população, especialmente nos anos iniciais da chegada do serviço.

Juntamente aos melhoramentos urbanos conduzidos pelos vereadores da Câmara Municipal é possível averiguar o movimento de transações de propriedades rurais e urbanas do município. Será que o esforço, por parte dos vereadores, para condução do 
processo de urbanização local foi acompanhado de uma evolução urbana considerando os imóveis registrados no município? Ou seja, será que no período de análise proposto por este trabalho, mais imóveis urbanos passavam a ser registrados, em detrimento do número de imóveis rurais? É o que será analisado na seção abaixo.

\section{Os registros de imóveis e as propriedades varginhenses: o rural e o urbano num município em formação}

Os registros de imóveis trazem informações bastante detalhadas sobre as propriedades registradas: os documentos começam com o número da ordem e a data, logo depois a freguesia do imóvel e sua denominação, como por exemplo, "sorte de terras" ou "fazenda", "Largo da Matriz" ou "casa e terreno". Assim, eram descritas depois as características dos imóveis: nos casos das fazendas, era informado sobre as casas de morada e de empregados, sobre as culturas e extensões de terras virgens, além de benfeitorias, como máquinas de beneficiar café, moinho ou monjolo; no caso dos imóveis urbanos, quando eram casas, as descrições eram bastante detalhadas: "casa de morada, coberta de telhas, assoalhada, envidraçada, com quintal fechado a muro de adobes", por exemplo.

Observando as características dos bens imóveis, eles foram separados em rurais e urbanos (parte essa que não continha nos documentos). Para tal separação, observou-se a descrição e localização da propriedade, se era uma casa de morada localizada em determinada rua, ou sortes de terras em uma fazenda, por exemplo. Em alguns casos, um único registro continha imóveis rurais e urbanos ${ }^{\mathrm{ix}}$. Depois, os registros seguiam com nome e local de residência do adquirente e do transmissor do imóvel.

Seguindo havia uma coluna para o título, que poderia ser compra/venda, compra/ venda e servidão ${ }^{x}$, permuta, acordo, dação em pagamento, dação in solutum, ou dação entre vivos ${ }^{\text {xi }}$, carta de arremataçãox ${ }^{\text {xii }}$, carta de adjudicação ${ }^{x i i i}$, demarcaçãoxiv, hipoteca de bens, herança ou cessão de direitos hereditários e, por fim, indenização por desapropriaçãa ${ }^{x v}$; na grande maioria dos casos, o título era compra/venda. A próxima coluna era a da forma do título, que poderia ser pública, particular, carta de arrematação, carta de adjudicação, forma de partilha ou certidão de pagamento.

\section{Os registros de imóveis no município de Varginha - o peso dos imóveis rurais}

Por meio do gráfico 1, é possível entender a evolução dos registros de imóveis para o município de Varginha (a cidade de Varginha mais os distritos de Pontal e Carmo da Cachoeira) ao longo do tempo. O número de propriedades transacionadas foi organizado por décadas. 
Gráfico 1: Evolução dos registros de imóveis rurais e urbanos no município de Varginha (1882-1920)

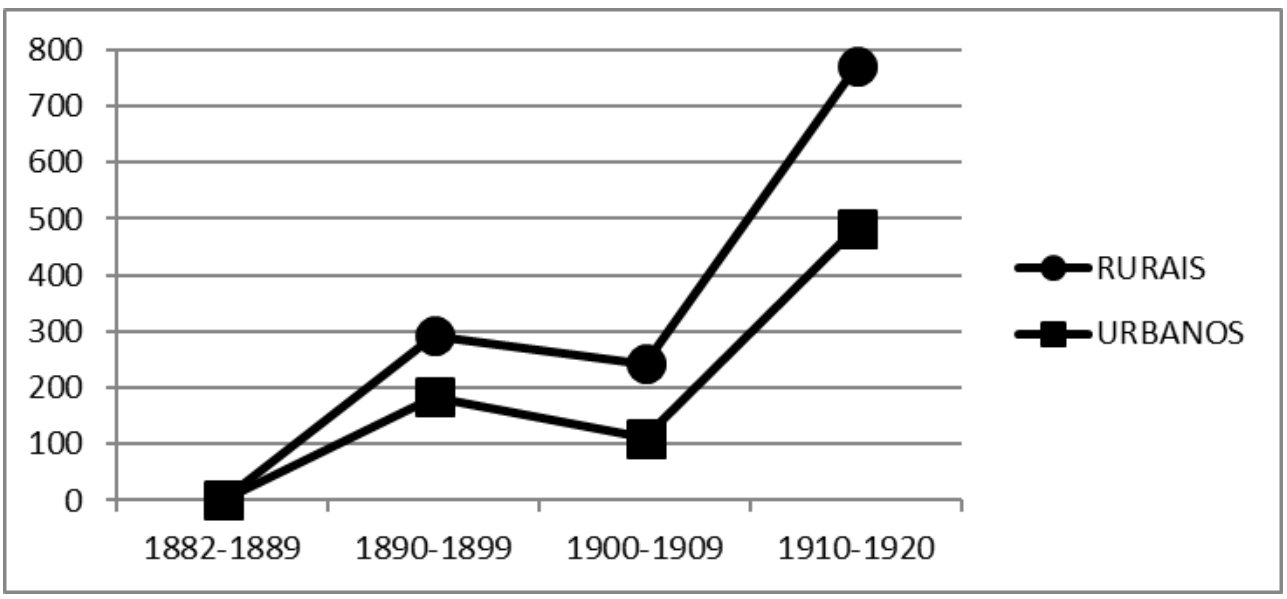

Fonte: Elaboração própria a partir dos Registros de Imóveis (1882-1920) presentes no CRIV.

Na primeira década de sua formação, quando Varginha acabava de ser elevada à categoria de vila, muitos dos imóveis ainda eram registrados em Três Pontas, município do qual Varginha foi emancipada. Assim, para o período de 1882 a 1889, tem-se para o município apenas um registro de imóvel rural, do distrito de Pontal.

Da primeira para a segunda década, o gráfico 1 mostra aumento dos dois tipos de propriedades: os registros de imóveis rurais aumentaram para 293 e os de imóveis urbanos eram de 183. O total de registros da década foi de 476. Assim, é possível perceber movimentação urbana, rural e financeira no município pelos registros de imóveis.

Na segunda década de formação da cidade, a elevação à sede de Comarca e as relações com os distritos e outros municípios foram marcos importantes. Assim, o aumento nos registros de imóveis se deve não apenas ao crescimento de Varginha, mas também dos distritos, embora dos distritos, a maioria dos registros fossem os rurais ${ }^{\mathrm{xvi}}$.

Da segunda para a terceira década, os registros de propriedades passaram por queda: os rurais caíram para 243 e os urbanos, para 111. O total de imóveis registrados para a década foi de 254. 0 motivo dessa queda nos registros não significa que o processo de urbanização desacelerava-se, pelo contrário, durante o período de 1900 a 1909, dois novos bairros surgiram na cidade de Varginha, o bairro das Três Bicas e a Vila Flamengo, fazendo-se aumentar o perímetro urbano (ÁVILA, 1983, p. 10). Não obstante, como os loteamentos foram criados naquele período, a povoação daqueles lugares ocorreu num período posterior. Provavelmente foi na década de 1910 que começaram a ser registrados imóveis referentes àqueles dois loteamentos.

o decrescimento do número de transações de imóveis para a terceira década de formação de Varginha foi contra o movimento natural de crescimento urbano do município. Contudo, uma plausível explicação para a queda nos imóveis registrados no período de 1900 a 1909 pode estar no fato de que a economia brasileira, nos primeiros anos do século XX, tenha passado por uma crise que refletiu também nas economias de cidades do interior do país ${ }^{x v i i}$. Como Varginha e os seus distritos estão próximos de cidades importantes do Brasil, como Rio de Janeiro e São Paulo, cidades estas que mantinham e ainda mantém relevantes relações com a economia internacional, talvez as crises pelas quais passou a economia brasileira e que afetaram as cidades maiores, 
tiveram impacto na sociedade varginhense, de forma que a economia decresceu e os registros de imóveis tenham passado por queda.

Chegando à década de 1910, o número de transações se eleva novamente: 771 bens rurais e 483 bens urbanos foram registrados. 0 total foi de 1.254 transações de imóveis. Os anos que mais apresentaram registros foram 1919 e 1920, com uma média de 230 bens imóveis registrados em cada um daqueles anos.

41 Na década de 1910 a cidade de Varginha passava por importantes transformações, como a chegada da energia elétrica, do telefone, dos bancos, a ferrovia transportava café não só da cidade, mas também do distrito de Carmo da Cachoeira e de outros municípios sul-mineiros. Ocorria uma maior movimentação no espaço urbano, com sua valorização. Os distritos também cresciam, embora num ritmo mais lento.

Valorizar o espaço urbano não significava apenas que ele passava a valer mais, em termos monetários, que as propriedades do espaço rural. Valorizar significava também que as pessoas passavam a querer habitar o espaço urbano, um novo costume de vida em meio a presença marcante do apego ao espaço rural. No entanto, por meio do gráfico 1, pode-se observar aumento de transações tanto dos imóveis rurais como dos urbanos ao longo de todo o período de 1882 a 1920: os imóveis rurais transacionados foram de 1.307 e as transações envolvendo imóveis urbanos foram de 778 , totalizando 2.085 registros. A maioria da população residia ainda no campo, embora o espaço urbano passasse por melhoramentos, sendo o movimento lento de transferência de populações das zonas rurais para as urbanas também observado para o Brasil como um todo, como poderá ser conferido no início do tópico 3.2 desta seção.

Considerando a aplicação em dinheiro que era direcionado para cada tipo de propriedade, para o primeiro período de análise constatou-se não haver bens imóveis urbanos, apenas um bem imóvel rural, do distrito de Pontal. Para a segunda década, tanto os bens imóveis rurais como os urbanos aumentaram de quantidade, mais os rurais que os urbanos, e o investimento caminha na mesma direção que a quantidade, sendo investido $82 \%$ do total em imóveis rurais e $18 \%$ em urbanos. No terceiro período de análise notou-se queda na quantidade de propriedades registradas, tanto rurais como urbanas, mas enquanto a porcentagem de investimento nos imóveis rurais também decrescia, ainda que pouco, comparada com o período anterior, o investimento nos bens imóveis urbanos aumentava, embora também pouco, pois investia-se cerca de $78 \%$ em imóveis rurais e $22 \%$ em imóveis urbanos. Finalmente, na quarta década, onde a quantidade de bens registrados passou por um considerável aumento, foram investidos 85\% em imóveis rurais e $15 \%$ em imóveis urbanos.

Ao longo do tempo, pode-se notar que, em média, aproximadamente $80 \%$ do dinheiro estava voltado para os imóveis rurais e aproximadamente $20 \%$ para os imóveis urbanos.

As propriedades rurais eram fazendas que, na maioria dos casos, eram bem equipadas: contavam com plantações (quantidades de café, milho, arroz, feijão, mandioca), mesmo que para consumo local; contavam com animais; com as casas de morada e de empregados; algumas possuíam máquina de beneficiar café, engenho, moinho e monjolo; ainda, muitas propriedades possuíam extensões de terras virgens, que possuíam valor monetário. Assim, claramente essas propriedades custavam mais dinheiro que as propriedades urbanas, que na maioria dos registros, eram casas de morada (que poderiam ser cobertas de telhas, assoalhadas, envidraçadas, feitas de 
tijolos, cercadas a muros de adobes, com quintal ou localizadas em ruas principais); terrenos, cercados ou não a muros; ou ainda, prédios e casas para negócios ${ }^{\text {xviii. }}$.

Os bens imóveis rurais representavam, de certa forma, poder e, por mais que houvesse um movimento de ampliação dos registros de imóveis urbanos, a base da riqueza da sociedade varginhense - e não apenas dela, mas de outros municípios que se formavam naquele contexto - estava na terra. Mesmo que houvesse um aumento nas transações de bens imóveis urbanos registrados, seus valores seriam menores que os valores das propriedades rurais, por se tratarem estas de grandes fazendas e/ou extensões de terras. 0 que não deve ser desconsiderado é que havia um crescimento das transações envolvendo bens imóveis urbanos, embora acompanhado de um crescimento nas transações envolvendo os imóveis rurais.

As análises feitas acima englobaram todo o conjunto de registros de imóveis considerando dados e informações de Varginha e dos distritos. Abaixo, as análises serão apenas para a cidade de Varginha.

\section{Os registros de imóveis na cidade de Varginha - valorização do espaço urbano}

A tabela 1 mostra o número de habitantes das áreas rurais e urbanas de Varginha, para a partir de 1940, que é quando foi possível observar a separação entre população urbana e rural:

Tabela 1: População rural e urbana de Varginha (1940-1980)

\begin{tabular}{|l|l|l|l|l|l|}
\hline \multirow{2}{*}{ DÉCADA } & \multicolumn{4}{l|}{ POPULAÇ̃̃O } \\
\cline { 2 - 6 } & RURAL & $\%$ & URBANA & $\%$ & TOTAL \\
\hline 1940 & 10.071 & 49,42 & 10.308 & 50,58 & 20.379 \\
\hline 1950 & 10.408 & 44,19 & 13.147 & 55,81 & 23.555 \\
\hline 1960 & 8.635 & 25,72 & 24.944 & 74,28 & 33.579 \\
\hline 1970 & 7.630 & 17,31 & 36.447 & 82,69 & 44.077 \\
\hline 1980 & 7.127 & 11,04 & 57.448 & 88,96 & 64.575 \\
\hline
\end{tabular}

Fonte: ÁVILA, 1983, p.09.

De acordo com dados do IBGE, o Brasil como um todo passou a ter mais habitantes nas áreas urbanas na década de 1960. Em Varginha, o aumento da população urbana em relação à rural ocorreu em 1940, apesar da diferença ter sido pequena, como mostra a tabela $1^{\text {xix }}$.

Essa mudança em relação à ocupação do espaço pode ser pensada considerando-se que a partir de 1920 o processo de industrialização no Brasil passou a ser mais forte que em períodos anteriores, especialmente no Sudeste do país. E o crescimento da indústria, de certa forma, absorve as pessoas para próximo das indústrias e dos setores de serviços, para as cidades. 
51 O gráfico 2 descrito abaixo mostra a evolução dos bens imóveis rurais e urbanos da cidade de Varginha ao longo do tempo, numa divisão feita por décadas:

Gráfico 2: Evolução dos registros de imóveis rurais e urbanos na cidade de Varginha (1890-1920)

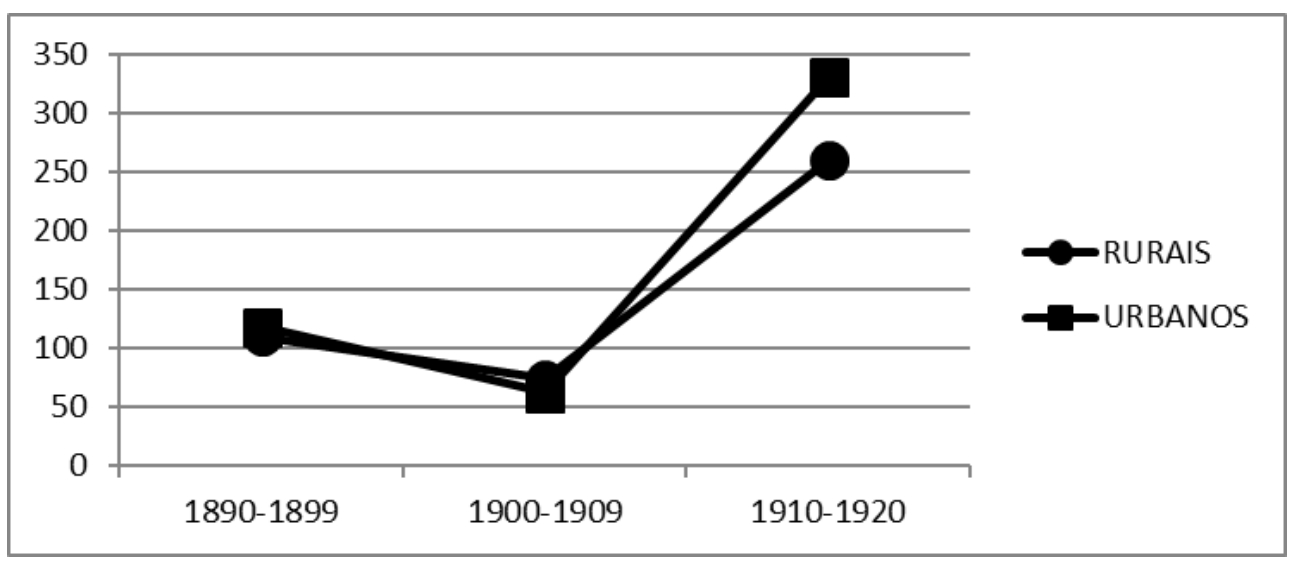

Fonte: Elaboração própria a partir dos Registros de Imóveis (1890-1920) presentes no CRIV.

Retirando os registros de Pontal e de Carmo da Cachoeira da análise, Varginha representava $45 \%$ do total dos 2.085 registros de imóveis.

Para os anos que vão de 1882 até 1889, o livro de registros mostrou apenas um registro $^{\mathrm{xx}}$, para o distrito de Pontal e, dessa forma, a análise para Varginha inicia-se na segunda década de formação da cidade, em 1890. Para a década, havia 110 registros para propriedades rurais e 118 para propriedades urbanas, sendo o total de 228 registros.

Para o período de 1900 a 1909, tem-se uma diminuição nas transações de imóveis registrados - assim como ocorreu na análise para Varginha juntamente com os distritos. Os registros de imóveis rurais do espaço correspondente à cidade de Varginha caíram para 74 e os de imóveis urbanos, para 62. O total de transações envolvendo os bens imóveis foi de 136. É uma diminuição considerável para os dois tipos de bens, os urbanos diminuem quase pela metade. E insiste-se em afirmar que poderiam ser as consequências do momento que a economia brasileira passava.

No entanto, é preciso frisar que a chegada da ferrovia mostra uma valorização do espaço urbano que não se restringiu apenas a década de sua inauguração, se estendendo para os anos iniciais do século XX:

Nas vias de acesso que surgem balizando ambos os lados do leito da estrada de ferro (...) aparecem, em inícios deste século [século XX], construções de porte e tipo inteiramente novos para a cidade, como galpões e armazéns de depósito, nos quais se instalam máquinas de beneficiamento de café, e estabelecimentos destinados ao comércio atacadista e de exportação desse produto, bem como algumas pequenas indústrias manufatureiras e de transformação, principalmente de laticínios e outros produtos alimentícios. (ÁVILA, 1983, p. 06).

No período de 1910 a 1920 foram registrados 260 imóveis rurais e 330 urbanos, totalizando 590 bens registrados em cartório, sendo os anos de 1919 e 1920 os que apresentaram a maior quantidade de registros (62 no ano de 1919 e 63 no ano de 1920). Foi nessa década que a cidade passou por maiores melhoramentos urbanos, como progressos no serviço de abastecimento de água, a chegada da energia elétrica, fábricas e instituições bancárias, o que atraía mais pessoas para o espaço urbano. 

pois em nenhum outro período constatou-se o número transações de propriedades urbanas sendo maior que o de transações envolvendo propriedades rurais na quantidade em que ocorreu no período de 1910 a 1920. A diferença era de 70 registros a mais para os imóveis urbanos. Movimento aquele comum em algumas outras cidades brasileiras na transição do século XIX para o século XX, que passavam por seus processos de urbanização. Em estudo similar para Ribeirão Preto, Renato Marcondes e Jorge de Oliveira escreveram que "desse modo, para esse importante município cafeicultor [Ribeirão Preto], verificamos movimentos distintos entre o número de escrituras rurais e urbanas ainda antes de 1930, sendo as primeiras mais frequentes no início do período e as segundas, no final" (MARCONDES; OLIVEIRA, 2013, p. 274-275).

Considerando o município de Varginha, pode-se afirmar que o peso maior dos imóveis rurais vinha dos distritos. Pontal foi emancipada em 1911 (mas imóveis da cidade continuaram sendo registrados em Varginha) e Carmo da Cachoeira, em 1938. Antes de tornarem-se cidades, é comum que nos distritos sejam comprados e vendidos mais imóveis rurais que urbanos. No caso específico de Varginha, foi depois de 1890 que os imóveis passaram a ser registrados na cidade - já que antes eram registrados em Três Pontas - e, um aumento mais relevante de registros urbanos ocorreu apenas depois de 1910.

Partindo para a análise do investimento em cada tipo de propriedade, tem-se o seguinte para a cidade de Varginha: para a década de 1890, se investia $76 \%$ de dinheiro em bens imóveis rurais e $24 \%$ em bens imóveis urbanos. Na década de 1900, o investimento era de $73 \%$ para imóveis rurais e $26 \%$ para imóveis urbanos. Finalmente, para a década de 1910, do total do investimento em imóveis, $66 \%$ estavam direcionados para os rurais e $34 \%$ para os urbanos. Isso mostra que, mesmo sendo a alocação de investimento sempre maior para os imóveis rurais, havia ascensão do investimento em imóveis urbanos, lenta, mas que pode ser vista ao longo do tempo.

60 A tabela descrita abaixo mostra os registros de imóveis em números ao longo do período de 1882 a 1920, considerando o município todo:

Tabela 2: Registros de imóveis do município de Varginha (1882-1920)

\begin{tabular}{|l|l|l|l|}
\hline CATEGORIAS & VARGINHA & DISTRITOS & MUNICÍPIO \\
\hline Imóveis Rurais (Q) & 444 & 863 & 1.307 \\
\hline Imóveis Urbanos (Q) & 510 & 268 & 778 \\
\hline TOTAL & $\mathbf{9 5 4}$ & $\mathbf{1 . 1 3 1}$ & $\mathbf{2 . 0 8 5}$ \\
\hline \% do I em Rurais & 69 & 76 & 83 \\
\hline \% do I em Urbanos & 31 & 24 & 17 \\
\hline TOTAL & $\mathbf{1 0 0}$ & $\mathbf{1 0 0}$ & $\mathbf{1 0 0}$ \\
\hline
\end{tabular}

Fonte: Elaboração própria a partir dos Registros de Imóveis (1890-1920) presentes no CRIV. Q = quantidade; $I$ = investimento

Espaço e Economia, 16 | 2019 
61 O peso das transações de imóveis rurais vinha mais dos distritos que da cidade de Varginha; no caso dos imóveis urbanos, a cidade registrou número bem maior de transações que os distritos. A porcentagem do investimento era sempre maior para as propriedades rurais, mas no caso da cidade de Varginha, o investimento em urbanos era maior que o investimento em urbanos considerando os distritos ou o município como um todo.

A economia varginhense tomava nova forma, tornava-se mais dinâmica: as áreas rurais concentravam a maior parte dos investimentos e propriedades transacionadas, mas acompanhadas de crescimento das áreas urbanas. O movimento era gradual, mas perceptível. Se em 1882, quando Varginha foi elevada à categoria de vila, não havia nenhum imóvel registrado, na década de 1910 eram 330 urbanos e 260 rurais.

63 A maioria da população varginhense, ainda em 1920, que é o ano de término da pesquisa, ocupava o espaço rural, mas o espaço urbano transformava-se e atraía pessoas para si, em meio às praças, aos comércios, às fábricas, aos bancos, ao teatro, enfim, aos componentes que surgem nas áreas urbanas, mas que não deixam de influenciar o campoxi.

\section{Considerações finais: movimentação urbana em Varginha}

64 As atas da Câmara Municipal revelaram o esforço dos vereadores varginhenses para inserção do município nas mudanças do cotidiano da passagem para o século XX, com a aprovação de diferentes projetos e leis relacionados ao espaço urbano: projetos relacionados a melhoramentos de ruas e praças, as melhorias no serviço de abastecimento de água, a inauguração da energia elétrica e a instalação do telefone, dentre outros, foram projetos elaborados tendo em conta as transformações urbanas que o Brasil passava.

Se as atas da Câmara mostraram transformações de maior vulto, o Código de Posturas expressou atenção com aquele espaço urbano através da incorporação de melhoramentos mais simples que, com o passar do tempo, fariam parte dos costumes de vida locais: a conservação de obras públicas (como pontes e calçadas), o asseio e o "embelezamento" de um espaço que antes não era tão relevante, o cuidado com as moradias e o seu entorno (zelo com as portas, janelas e muros das casas), a proibição da criação de certos animais no centro do município.

Os registros de imóveis trouxeram informações sobre as transações de imóveis rurais e urbanos do município varginhense. Ainda que durante todo o período de 1882 até 1920 tenham sido registradas mais propriedades rurais que urbanas para o município como um todo, e que o investimento monetário tenha sido sempre maior para os imóveis rurais - dado o preço maior desses imóveis em comparação aos urbanos - é possível observar por meio dos registros de imóveis, com o passar do tempo, que as propriedades urbanas passavam por valorização, especialmente na cidade de Varginha, pois o peso das transações de imóveis rurais, bem como do investimento em tais bens, vinha mais dos distritos que da cidade.

Das propriedades rurais às propriedades urbanas, passando pelos melhoramentos do espaço exterior ao das moradias, é possível afirmar que o município de Varginha passava por movimentação urbana. 
As mudanças mais simples relacionadas ao espaço urbano (descritas pelo Código de Posturas), a chegada das empresas de serviços urbanos (como foi visto nas atas da Câmara), bem como as transações de propriedades do município (o que expressaram os registros de imóveis rurais e urbanos) eram novidades para o contexto de formação de Varginha, que estavam inseridas num contexto maior, de modernização de padrões de consumo, de melhoramentos urbanos e de alterações nos hábitos de vida do Brasil como um todo, como consequência de transformações impostas pela Segunda Revolução Industrial, numa época de Belle Époque.

\section{BIBLIOGRAFIA}

\section{Fontes manuscritas}

ACMV - Atas da Câmara Municipal de Varginha, dos anos de 1882 a 1917, depositadas no Museu Municipal da cidade de Varginha (MMV).

Inventário post-mortem de Matheus Tavares da Silva, 1905, localizado no Arquivo Permanente do Tribunal de Justiça de Minas Gerais, na cidade de Contagem.

Registros de Imóveis, do período de 1882 a 1920, presentes no Cartório de Registros de Imóveis da cidade de Varginha (CRIV).

Fontes impressas

CPV - Código de Posturas da Cidade de Varginha. Livro da Lei Mineira, 1888, p. 340-365.

VEIGA, Bernardo Saturnino da. Almanach Sul-Mineiro para 1884. Campanha: Typographia do Monitor Sul-Mineiro, 1884.

\section{Bibliografia}

ALMEIDA, Rômulo Barreto de. Traços da História Econômica da Bahia no último século e meio. RDE - Revista de Desenvolvimento Econômico. Ano XI 2009, Salvador-BA, ano XI, n. 19 / p. 82-101, janeeiro de 2009.

ÁVILA, Affonso. Varginha: formação e evolução. Fundação João Pinheiro, Belo Horizonte, 13 (7/8), pp. 02-18, jul./ago., 1983.

BONA, Avelino de. Títulos Judiciais no Registro de Imóveis. Porto Alegre: Sagra-Luzzatto, 1996.

BUENO, Ricardo. Borracha na Amazônia: As cicatrizes de um ciclo fugaz e o início da industrialização. Porto Alegre: Quattro Projetos, 2012.

CANO, Wilson. Raízes da Concentração Industrial em São Paulo. 1975. Tese (Doutorado em Ciências Econômicas) - Instituto de Filosofia e Ciências Humanas, Universidade Estadual de Campinas. Campinas, 1975.

CANO, Wilson. Da Década de 1920 à de 1930: Transição Rumo à Crise e à Industrialização no Brasil. EconomiA. Brasília, v. 13, n. 3b, pp. 897-916, set./dez., 2012. 
FIGUEIREDO JÚNIOR, Gilvando Furtado de. Dação em Pagamento envolvendo Bens Imóveis nas dissoluções societárias. Disponível em: http://oabce.org.br/wp-content/uploads/2014/09/sSOCIET\%C3\%81RIAS.pdf. Acesso em 26/02/2019.

FRAGOSO, João Luís Ribeiro. Comerciantes, fazendeiros e formas de acumulação em uma economia escravista-colonial: Rio de Janeiro, 1790-1888. Rio de Janeiro, 1990. Tese (Doutorado em História) - ICHF/Universidade Federal Fluminense.

HERRLEIN Júnior, Ronaldo. Rio Grande do Sul, 1889-1930: Um outro capitalismo no Brasil meridional? 2000. Tese (Doutorado em História Econômica) - Instituto de Economia, Universidade Estadual de Campinas. Campinas, 2000.

LIMA, João Heraldo. Café e Indústria em Minas Gerais (1870-1920). 1977. Dissertação (Mestrado em Economia) - Instituto de Filosofia e Ciências Humanas, Universidade Estadual de Campinas. Campinas, 1977.

MARCONDES, Renato Leite; OLIVEIRA, Jorge Henrique Caldeira de. Trocando de mãos: o mercado de imóveis rurais em Ribeirão Preto (1874-1930). In: Economia e Sociedade, Campinas, v. 22, n. 1 (47), p. 263-285, abr. 2013.

MARINS, Paulo César Garcez. "Habitação e vizinhança: limites da privacidade no surgimento das metrópoles brasileiras”. In: SEVCENKO, Nicolau. História da Vida Privada no Brasil - República: da Belle Époque à Era do Rádio. São Paulo: Companhia das Letras, 1998.

PAIVA, João Pedro Lamana. Títulos Judiciais e a sua repercussão registral no RI. Disponível em: http://www.mprs.mp.br/areas/urbanistico/arquivos/artigopaiva.pdf. Acesso em 26/02/2019.

SAES, Alexandre Macchione. Conflitos do Capital: Light versus CBEE na Formação do Capitalismo Brasileiro (1898 - 1927). 2008. Tese (Doutorado em Desenvolvimento Econômico) - Instituto de Economia, Universidade Estadual de Campinas. Campinas, 2008.

SAES, Alexandre Macchione; MARTINS, Marcos Lobato; GAMBI, Thiago Fontelas Rosado (Orgs.). Sul de Minas em Urbanização - Modernização Urbana no início do século XX. São Paulo: Alameda, 2016.

SAES, Alexandre Macchione; COSENTINO, Daniel do Val; GAMBI, Thiago Fontelas Rosado. Sul de Minas em Transição: opção por uma regionalização como ponto de partida. In: SAES, Alexandre Macchione; MARTINS, Marcos Lobato (Orgs.). Sul de Minas em Transição - A formação do Capitalismo na passagem para o século 20. São Paulo: Edusc, 2012.

SALES, José Roberto. Espírito Santo da Varginha (MG) - 1763-1920. Varginha: Gráfica Editora Sul Mineira, 2003.

SEVCENKO, Nicolau. "Introdução. O prelúdio republicano, astúcias da ordem e ilusões do progresso". In: . História da Vida Privada no Brasil - República: da Belle Époque à Era do Rádio. São Paulo: Companhia das Letras, 1998.

VILLELA, Annibal Vilanova; SUZIGAN, Wilson. Política do governo e crescimento da economia brasileira - 1889-1945. 3 ed. Brasília: IPEA, 2001.

WILLIAMS, Raymond. o Campo e a Cidade na História e na Literatura. Tradução de Paulo Henriques Brito. São Paulo: Companhia das Letras, 2011.

WIRTH, John. O Fiel da Balança: Minas Gerais na Federação Brasileira (1889-1937). Rio de Janeiro: Paz e terra, 1982. 


\section{NOTAS DE FIM}

i. Fragmento da ata da primeira reunião da Câmara Municipal de Varginha, coordenada pelo presidente da Câmara de Três Pontas (município ao qual Varginha pertencia antes da emancipação).

ii. A referência ao município de Varginha diz respeito à cidade de Varginha e aos distritos de Pontal e Carmo da Cachoeira. A referência à cidade envolve apenas o espaço físico de Varginha, sem considerar os distritos.

iii. Major Matheus Tavares da Silva, influente membro da sociedade varginhense, foi descrito no Almanach Sul-Mineiro para 1884 como capitalista, negociante, fazendeiro com engenho movido por água, tropeiro e açougueiro. (VEIGA, 1884, p. 187-189). Dentre os moradores do município de Varginha na transição do século XIX para o XX, foi um dos membros que mais posses detinha. Faleceu em 1905 deixando dois filhos.

iv. Descrito no Almanach Sul-Mineiro para 1884 como proprietário de estabelecimento de secos e molhados (VEIGA, 1884, p. 187).

v. Três anos depois daquele registro na ata, o Código de Posturas varginhense, em seu capítulo IX, na seção "das obras publicas", dizia que "a conservação e reparos de pontes, calçadas regos, aqueductos, poços, tanques, muralhas, paredões ou quaesquer outras obras, feitas para segurança de edifícios ou prisões publicas, e todas as construcções em benefício commum ou para decoração das povoações, serão feitas pela camara" (CPV, 1888, p. 351).

vi. Sobre transformações urbanas de outros municípios do Sul de Minas Gerais na passagem do século XIX para o século XX, cf.: SAES; MARTINS; GAMBI, 2016, parte 2 Sul de Minas em urbanização: estudos de caso.

vii. Para o período de 1882 a 1920, 275 inventários post-mortem foram encontrados para o município de Varginha. Considerando o valor monetário do monte-mor dos inventariados em contos de réis, o major Matheus Tavares da Silva era o dono da maior fortuna, uma riqueza de 444:273\$764.

viii. A amostra de inventários do município de Varginha mostrou grande concentração de riqueza. De 275 documentos, apenas 11 deles concentravam $55,70 \%$ da riqueza total da amostra. Aquele estrato social investia grande parte de seu monte-mor nos bens imóveis rurais, era uma elite agrária. Para mais detalhes sobre a elite agrária de Varginha entre o final do século XIX e o início do século XX, ver: Autor, data.

ix. No livro de registros, algumas propriedades eram denominadas, ao mesmo tempo, como rurais e urbanas. Nesses casos, foram contabilizados duas vezes esses registros, uma vez como propriedade rural e uma vez como urbana. No caso do valor monetário, como não é possível saber a quantia exata pertencente a cada imóvel, foi contabilizado também duas vezes, sendo uma vez o valor direcionado para o imóvel rural e uma vez para o imóvel urbano.

x. Servidão implica em direito que o proprietário do imóvel pode ter durante algum período de tempo, depois que o imóvel foi vendido (PAIVA, p. 20). No caso de um bem imóvel transacionado, o vendedor poderia ter o direito de residir na casa vendida durante cinco anos, por exemplo, para depois o comprador passar a residir nela. xi. Dação em pagamento, dação in solutum e dação entre vivos são sinônimos, embora nos registros os termos fossem descritos de formas diferentes (FIGUEIREDO JR., s/d, p. 01). Nada mais é que um pagamento feito.

xii. Caso de imóveis colocados em hasta pública, sendo vendidos por quem pagasse o maior valor por eles. 
xiii. “A adjudicação só é admitida de bens imóveis e realiza-se com a transferência forçada do imóvel constrito ao credor, que resolve preferir ao arrematante, configurando essa alienação judicial autêntica dação em pagamento" (BONA, 1996, p. $111)$.

xiv. Os registros que continham demarcação no título eram todos rurais, sem transmissores, apenas com adquirentes. Assim, acredita-se que esses registros eram de terras que simplesmente foram marcadas ou delimitadas.

xv. Indenização por desapropriação ocorreu nos casos dos terrenos que foram desapropriados para a passagem da estrada de ferro.

xvi. Essa informação poderá ser confirmada no tópico 3.2. deste artigo, quando será analisada apenas a cidade de Varginha.

xvii. Escreveram Villela e Suzigan (2001, p. 28) que "finalmente, embora não se disponha de indicadores macroeconômicos para a época [de 1899 até 1902], é quase certo que a política de deflação deve ter causado queda no nível de atividade econômica". Ainda, "em 1908, porém, ocorreu uma crise internacional, acarretando a redução dos níveis globais do comércio exterior". Aqueles eventos que ocorreram no início do século XX, tendo afetado de forma mais profunda as grandes cidades, podem também ter gerado consequências para o crescimento urbano e econômico naquele período específico para os municípios menores, do interior do Brasil, como Varginha. xviii. Em estudo para Ribeirão Preto entre 1874 e 1930, Renato Marcondes e Jorge de Oliveira (2013) escreveram, comparando os imóveis rurais com os urbanos que, no caso das transações de imóveis rurais, "o valor médio dessas escrituras atingiu quase quinze contos contra um valor médio de pouco mais de dois contos de réis para as escrituras urbanas, reforçando o caráter rural da sociedade daquela época. Essas diferenças de médias mostraram-se compreensíveis, dado que, no meio urbano, as negociações restringiam-se a casas e terrenos e, no meio rural, os negócios envolviam muitas vezes terras com mais de 100 alqueires e culturas valorizadas, como a do café" MARCONDES; OLIVEIRA, 2013, p. 272).

xix. É importante destacar que Varginha situa-se no Sudeste do país, próximo de cidades de importância econômica, em que a passagem das pessoas do campo para as cidades ocorreu mais cedo que em lugares como o Nordeste do país. Sendo assim, no Sudeste, o peso da população urbana pode ter sido maior que o peso da população rural logo em meados do século XX, tendo esse fato refletido sobre Varginha.

xx. Cabe ressaltar que, da mesma forma que o distrito de Pontal, por exemplo, mesmo depois da emancipação em 1911, teve ainda bens imóveis registrados em Varginha, também Varginha certamente teve registros de imóveis feitos em Três Pontas (município ao qual Varginha pertencia) depois da emancipação.

xxi. "O campo passou a ser associado a uma forma mais natural de vida - de paz, inocência e virtudes simples (...). À cidade associou-se a ideia de centro de realizações de saber, comunicações (...) Também a cidade aparece sob numerosas formas: capital do Estado, centro administrativo, centro religioso, centro comercial (...)" (WILLIAMS, 2011, p. 11).

\section{RESUMOS}

A passagem para o século XX foi uma época em que, em diferentes regiões do Brasil, cidades passavam por crescimento econômico e urbanização. Naquele contexto, o município de Varginha, 
situado ao Sul de Minas Gerais, foi emancipado em 1882. Assim, este trabalho objetiva compreender os melhoramentos urbanos do município de Varginha, partindo de dois grupos de fontes principais: atas da Câmara Municipal, do período de 1882 a 1917, e registros de imóveis, dos anos de 1882 a 1920. Por meio das fontes, foi possível constatar transformações no espaço do município nascente: as atas da Câmara expressaram o esforço dos vereadores para a aprovação de projetos e leis voltados para o espaço urbano; os registros de imóveis apontaram que, ainda que o número de propriedades transacionadas e o investimento monetário tenham sido mais expressivos para os imóveis rurais em todo período de análise, aos poucos, em meio ao apego o rural, os moradores de Varginha valorizavam o espaço e os imóveis urbanos.

The transition to the twentieth century was a time when, in different regions of Brazil, cities were experiencing economic growth and urbanization. In this context, the municipality of Varginha, located in the south of Minas Gerais, was emancipated in 1882. Thus, this work aims to understand the urban improvements of the municipality of Varginha, starting from two groups of main sources: City Council minutes, from 1882 to 1917, and property records, from 1882 to 1920. Through the sources, it was possible to verify transformations in the space of the nascent municipality: the minutes of City Council expressed the effort of the councilmen for the approval of projects and laws directed to the urban space; the property records pointed out that, although the number of properties transacted and the monetary investment were more expressive for rural properties throughout the period of analysis, little by little, in the midst of attachment to the rural, the residents of Varginha valued the urban space and the urban properties.

El paso hacia el siglo XX fue una época en que, en diferentes regiones de Brasil, ciudades pasaban por crecimiento económico y urbanización. En ese contexto, el municipio de Varginha, situado al sur de Minas Gerais, fue emancipado en 1882. Así, este trabajo objetiva comprender las mejoras urbanas del municipio de Varginha, partiendo de dos grupos de fuentes principales: actas del Ayuntamiento, de 1882 a 1917, y registros de inmuebles, de los años 1882 a 1920. Por medio de las fuentes, fue posible constatar transformaciones en el espacio del municipio naciente: las actas de la Cámara expresaron el esfuerzo de los concejales para la aprobación de proyectos y leyes orientados hacia el espacio urbano; los registros de inmuebles apuntaron que, aunque el número de propiedades transaccionadas y la inversión monetaria fueran más expresivas para los inmuebles rurales en todo período de análisis, poco a poco, en medio del apego al rural, los habitantes de Varginha valorizaban el espacio y, los inmuebles urbanos.

La transition vers le XXe siècle a été une période où, dans différentes régions du Brésil, les villes connaissaient une croissance économique et une urbanisation. Dans ce contexte, la municipalité de Varginha, située au sud du Minas Gerais, a été émancipée en 1882. Ainsi, ce travail vise à comprendre les améliorations urbaines de la municipalité de Varginha, à partir de deux groupes de sources principales: le procès-verbal de la mairie, de la période de 1882 à 1917, et les registres immobiliers de 1882 à 1920. Grâce aux sources, il a été possible de vérifier les transformations dans l'espace de la municipalité naissante: le procès-verbal de la Chambre exprimait les efforts des conseillers pour l'approbation des projets et des lois destinés à la espace urbain; Les dossiers immobiliers ont indiqué que, bien que le nombre de propriétés échangées et l'investissement monétaire aient été plus importants pour les propriétés rurales tout au long de la période d'analyse, peu à peu, au milieu de l'attachement rural, les résidents de Varginha ont apprécié l'espace et l'immobilier urbain. 
ÍNDICE

Mots-clés: Immobilier rural. Immobilier urbain. Améliorations urbaines. Varginha. 19e et 20e siècles.

Keywords: Rural properties. Urban properties. Urban improvements. Varginha. 19th and 20th centuries.

Palabras claves: Inmuebles rurales. Inmuebles urbanos. Mejoras urbanas. Varginha. Siglos XIX y XX.

Palavras-chave: Imóveis rurais. Imóveis urbanos. Melhoramentos urbanos. Varginha. Séculos XIX e XX.

\section{AUTOR}

\section{NATÂNIA SILVA FERREIRA}

Graduada em Ciências Econômicas pela UNIFAL-MG, Mestre em História Econômica pela USP. Doutoranda do programa de Desenvolvimento Econômico da UNICAMP.

natania.silvaferreira@gmail.com 